\title{
Long-term imaging characteristics of clinical complete responders during watch-and-wait for rectal cancer-an evaluation of over 1500 MRIs
}

Citation for published version (APA):

Lambregts, D. M. J., Maas, M., Boellaard, T. N., Delli Pizzi, A., van der Sande, M. E., Hupkens, B. J. P., Lahaye, M. J., Bakers, F. C. H., Beets, G. L., \& Beets-Tan, R. G. H. (2020). Long-term imaging characteristics of clinical complete responders during watch-and-wait for rectal cancer-an evaluation of over 1500 MRIs. European Radiology, 30(1), 272-280. https://doi.org/10.1007/s00330-019-06396-1

Document status and date:

Published: 01/01/2020

DOI:

10.1007/s00330-019-06396-1

Document Version:

Publisher's PDF, also known as Version of record

Document license:

Taverne

Please check the document version of this publication:

- A submitted manuscript is the version of the article upon submission and before peer-review. There can be important differences between the submitted version and the official published version of record.

People interested in the research are advised to contact the author for the final version of the publication, or visit the DOI to the publisher's website.

- The final author version and the galley proof are versions of the publication after peer review.

- The final published version features the final layout of the paper including the volume, issue and page numbers.

Link to publication

\footnotetext{
General rights rights.

- You may freely distribute the URL identifying the publication in the public portal. please follow below link for the End User Agreement:

www.umlib.nl/taverne-license

Take down policy

If you believe that this document breaches copyright please contact us at:

repository@maastrichtuniversity.nl

providing details and we will investigate your claim.
}

Copyright and moral rights for the publications made accessible in the public portal are retained by the authors and/or other copyright owners and it is a condition of accessing publications that users recognise and abide by the legal requirements associated with these

- Users may download and print one copy of any publication from the public portal for the purpose of private study or research.

- You may not further distribute the material or use it for any profit-making activity or commercial gain

If the publication is distributed under the terms of Article $25 \mathrm{fa}$ of the Dutch Copyright Act, indicated by the "Taverne" license above, 


\title{
Long-term imaging characteristics of clinical complete responders during watch-and-wait for rectal cancer-an evaluation of over 1500 MRIs
}

\author{
Doenja M. J. Lambregts ${ }^{1}$ (1) Monique Maas ${ }^{1} \cdot$ Thierry N. Boellaard $^{1} \cdot$ Andrea Delli Pizzi $^{2} \cdot$ Marit E. van der Sande $^{3,4}$. \\ Britt J. P. Hupkens ${ }^{4,5}$ • Max J. Lahaye ${ }^{1}$. Frans C. H. Bakers ${ }^{6} \cdot$ Geerard L. Beets ${ }^{3,4}$ • Regina G. H. Beets-Tan ${ }^{1,4}$
}

Received: 3 April 2019 /Revised: 24 June 2019 / Accepted: 26 July 2019/Published online: 19 August 2019

(C) European Society of Radiology 2019

\begin{abstract}
Objectives Rectal cancer patients with a clinical complete response after chemoradiotherapy (CRT) may be followed with a 'watch-and-wait' (W\&W) approach as an alternative to surgery. MRI plays an important role in the follow-up of these patients, but basic knowledge on what to expect from the morphology of the irradiated tumour bed during follow-up is lacking, which can hamper image interpretation. The objective was to establish the spectrum of non-suspicious findings during long-term ( $>2$ years) follow-up in patients with a sustained clinical complete response undergoing W\&W.

Methods A total of 1509 T2W MRIs of 164 sustained complete responders undergoing W\&W were retrospectively evaluated. Morphology of the tumour bed was evaluated (2 independent readers) on the restaging MRI and on the various follow-up MRIs and classified as (a) no fibrosis, (b) minimal fibrosis, (c) full thickness fibrosis, or (d) irregular fibrosis. Any changes occurring during follow-up were documented.

Results A total of 104 patients (63\%) showed minimal fibrosis, 38 (23\%) full thickness fibrosis, 8 (5\%) irregular fibrosis, and 14 (9\%) no fibrosis. In $93 \%$ of patients, the morphology remained completely stable during follow-up; in $7 \%$, a minor increase/ decrease in fibrosis was observed. Interobserver agreement was excellent $(\kappa 0.90)$.

Conclusions Typically, the morphology as established at restaging remains completely unchanged. The majority of patients show fibrosis with the predominant pattern being a minimal fibrosis confined to the rectal wall. Complete absence of fibrosis occurs in only $1 / 10$ cases. Once validated in independent cohorts, these findings may serve as a reference for radiologists involved in the clinical follow-up of W\&W patients.

Key Points

- In rectal cancer patients with a sustained complete response after chemoradiation, the rectal wall morphology as established on restaging MRI typically remains unchanged during long-term MRI follow-up.

- The vast majority of complete responders show fibrosis with the predominant pattern being a minimal fibrotic remnant that remains confined to the rectal wall; complete absence of fibrosis occurs in only $10 \%$ of the cases.

- Once validated in independent cohorts, the findings of this study may serve as a reference for radiologists involved in the clinical follow-up of rectal cancer patients undergoing watch-and-wait.
\end{abstract}

Keywords Rectal neoplasms $\cdot$ Magnetic resonance imaging $\cdot$ Fibrosis

Doenja M. J. Lambregts

d.lambregts@nki.nl

1 Department of Radiology, Netherlands Cancer Institute, PO Box 90203, 1006 BE Amsterdam, The Netherlands

2 ITAB - Institute of Advanced Biomedical Technologies, "G. d'Annunzio" University, Chieti, Italy
3 Department of Surgery, Netherlands Cancer Institute, Amsterdam, The Netherlands

4 GROW School for Oncology and Developmental Biology University of Maastricht, Maastricht, The Netherlands

5 Department of Surgery, Maastricht University Medical Centre, Maastricht, The Netherlands

6 Department of Radiology, Maastricht University Medical Centre, Maastricht, The Netherlands 


$\begin{array}{ll}\text { Abbreviations } \\ \text { CRT } & \begin{array}{l}\text { Chemoradiotherapy } \\ \text { DWI }\end{array} \\ \text { Diffusion-weighted imaging } \\ \text { ESGAR } & \begin{array}{l}\text { European Society of Gastrointestinal } \\ \text { and Abdominal Radiology }\end{array} \\ \text { FSE } & \text { Fast spin echo } \\ \text { FU } & \text { Follow-up } \\ \text { T2W } & \text { T2-weighted } \\ \text { W\&W } & \text { Watch-and-wait }\end{array}$

\section{Introduction}

Organ-preserving treatment is increasingly considered as an alternative to major surgery in rectal cancer patients that respond very well to neoadjuvant treatment. Studies have shown good oncological and functional outcomes for a watch-andwait $(W \& W)$ approach in patients with a clinical complete response after neoadjuvant chemoradiotherapy (CRT) [1-5]. Recently, long-term outcome was published of a large registry study of 880 clinical complete responders undergoing W\&W in 47 institutes from 15 different countries. Results showed good 5-year overall and disease-free survival of $85 \%$ and $94 \%$, respectively, for patients with a sustained complete response. Twenty-five percent of patients developed a local regrowth in the first 2 years, almost exclusively located in the bowel wall. These patients can typically be managed with salvage surgery, resulting in similar outcomes compared to non-complete responders who are immediately operated after CRT [6].

An important prerequisite of the W\&W strategy is to ensure adequate follow-up (FU) so that tumour regrowths can be detected as early as possible to allow for timely salvage surgery. Although follow-up strategies differ between reports and institutions, the two mainstays of follow-up are flexible endoscopy and MRI. Main signs indicative of a luminal tumour regrowth on MRI are the re-appearance of an intermediate signal intensity mass within the irradiated tumour bed on T2-weighted (T2W) MRI combined with focal high signal intensity on diffusion-weighted imaging (DWI) when available [7]. Absence of these findings favours the diagnosis of a sustained complete response. Although thus seemingly straightforward, interpretation of the morphology of the rectal wall on follow-up T2W MRI can be challenging since - due to the relative novelty of the W\&W approach - basic knowledge on what to expect from the morphology of the 'normal' irradiated tumour bed during long-term follow-up is lacking. This is a knowledge gap that needs to be overcome as radiologists are now confronted with a new type of follow-up imaging without an evidence-based reference for normal posttherapy findings. In 2011, a first pilot study was published showing, in a small group of $n=19 \mathrm{~W} \& \mathrm{~W}$ patients, that the morphology of the rectal wall could roughly be categorised into four patterns ranging from complete absence of fibrosis ('normalization of the rectal wall') to various degrees of minimal, thick, or spiculated fibrosis, which tended to remain consistent over time [8]. So far, these findings have not been validated in larger patient cohorts.

The aim of the current study is to add to these previous data by studying a large cohort of rectal cancer patients with a sustained clinical complete response for more than 2 years after chemoradiotherapy in order to strengthen the evidence on the spectrum of 'normal' (non-suspicious) long-term morphological MRI findings on standard T2-weighted MRI in this group. Since the primary focus is to assess the morphology of the rectal wall on T2W MRI, evaluation of DWI-although of clinical importance-was outside the scope of the current study [7]. The findings of this study—once validated by other groups - can serve as a potential reference for future research and for radiologists involved in the clinical follow-up of patients undergoing watch-and-wait.

\section{Methods}

\section{Patients}

For this study, the MR images of 164 rectal cancer patients with a sustained clinical complete response for at least 2 years after inclusion in a watch-and-wait protocol (2010-2016) were retrospectively evaluated. As part of the follow-up program, patients were routinely monitored with MRI (combined with digital rectal examination and endoscopy), performed every 3 months during the first year, and then every 6 months (until a total of 5 years). Patients were all selected from previously published or ongoing clinical studies focussing on the clinical outcome of organ preservation $[2,6,9$; NCT03426397]. Ethical review board approval was obtained for this retrospective imaging study and informed consent was waived. Patients were included if they (a) completed a long course of neoadjuvant treatment for biopsy-proven primary rectal adenocarcinoma, (b) were included in a watch-andwait program, and (c) had a sustained clinical complete response with no signs of a local tumour regrowth (on imaging and endoscopy \pm biopsies) during a follow-up period of at least 2 years. This cut-off was chosen as it is known that the vast majority of local recurrences in patients undergoing $\mathrm{W} \& \mathrm{~W}$ occur in the first 2 years of follow-up [6].

\section{MR imaging}

Patients underwent an MRI for primary staging (pretreatment) and a second MRI for restaging and response evaluation, which was routinely performed between 8 and 10 weeks after completion of neoadjuvant therapy. After inclusion into the watch-and-wait program, patients routinely underwent MRI 
every 3 months in the first year of follow-up and then every 6 months in years $2-5$ as described above. Follow-up MRIs were performed at $1.5 \mathrm{~T}$ (Achieva or Ingenia MR System, Philips Healthcare). The protocol included T2-weighted fast spin echo (FSE) sequences in 3 planes. The transverse and coronal $\mathrm{T} 2$-weighted sequences were angulated perpendicular and parallel to the former tumour axis, respectively, with consistent imaging planes over time. Slice thickness was $3 \mathrm{~mm}$ with an in-plane resolution of $0.78 \times 0.78 \mathrm{~mm}$. Echo time was set at $130 \mathrm{~ms}$ with a variable repetition time ('shortest'). Spasmolytics were not routinely given.

\section{Image evaluation}

The morphological T2-weighted MR images were independently evaluated by two experienced rectal MRI readers (TNB and ADP), who assessed the morphology of the tumour bed on the restaging MRI (with reference to the primary staging scan) and on the various consecutive follow-up MRIs. First, the two readers classified the morphologic pattern on the restaging MRI as (a) no fibrosis, (b) minimal fibrosis, (c) full thickness fibrosis, or (d) irregular fibrosis, according to a classification system previously reported [8]. Imaging examples of these four morphologic patterns are provided in Fig. 1. When no residual tumour mass or hypointense fibrosis could be detected at the site of the previous tumour, the pattern was classified as 'no fibrosis' (Fig. 1a). 'Minimal fibrosis' was defined as a small area of hypointense fibrosis that remains restricted to the rectal wall, causing only minimal local thickening of the rectal wall (Fig. 1b). Full thickness fibrosis was defined as a more pronounced (mass-like) hypointense fibrotic thickening of the rectal wall at the site of the previous tumour (Fig. 1c). 'Irregular fibrosis' was defined as a fibrotic mass or wall thickening with irregular and/or spiculated margins (Fig. 1d). Second, the readers recorded whether any changes in rectal wall morphology (i.e. change in pattern, subjective increase or decrease in the size of the fibrosis) were visually apparent on any of the sequential follow-up
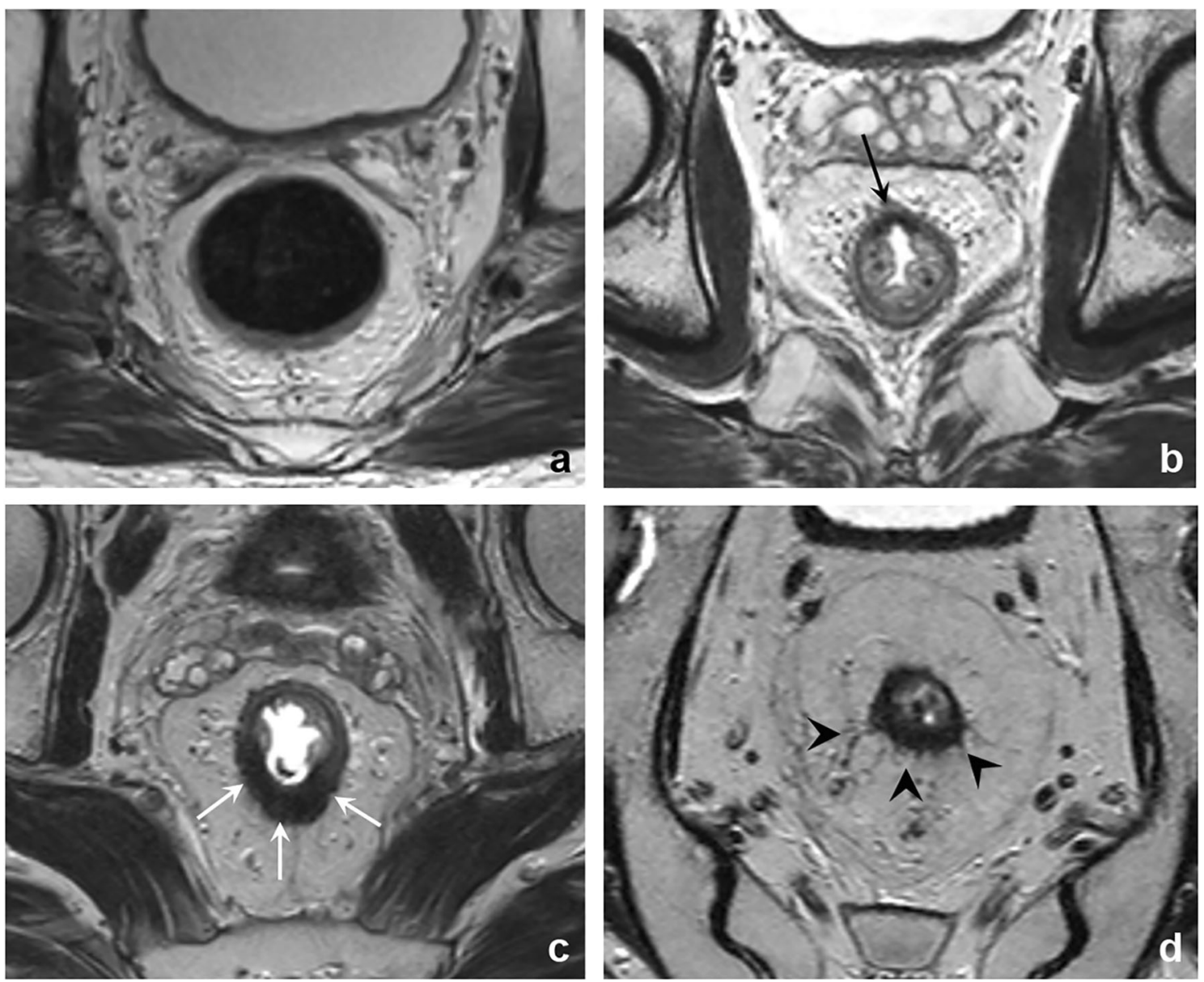

Fig. 1 The morphology of the rectal wall was categorised as (a) 'absence of fibrosis' (apparent normalization), when no hypointense residue could be detected at the site of the previous tumour, (b) 'minimal fibrosis' when only a small area of hypointense fibrosis confined to the bowel wall was observed (black arrow) causing only a minimal local thickening of the

rectal wall, (c) 'full thickness fibrosis' when a more pronounced masslike fibrotic thickening was observed (white arrows), and (d)'irregular fibrosis' when a fibrotic mass or wall thickening with irregular and/or spiculated margins was observed (black arrowheads) 
examinations. In case of any discrepancies in the scoring between the two readers, a third reader (DMJL, a rectal MRI expert with $>9$ years specific rectal MRI experience) was consulted to reach final consensus. The morphology of the tumour pretreatment (on the primary staging MRI) was documented and classified as 'polypoid', 'semi-circular', or 'bulky/irregular', according to classifications previously reported $[7,10]$.

\section{Data analysis}

Data was analysed with IBM SPSS Statistics 22 (IBM Corp. 2013). The distribution (\%) of the four morphologic patterns amongst the study patients as well as any changes in morphology over time was assessed using descriptive statistics. Interobserver agreement was assessed using quadratic weighted kappa analysis.

\section{Results}

\section{Patient characteristics}

Baseline patient characteristics are presented in Table 1. At the time of analysis, the 164 study patients together had underwent a total of 1509 MRI examinations (164 primary staging examinations, 164 restaging examinations, and 1181 follow-up MRIs). The median number of follow-up MRIs analysed per patient was 7 (range 3-14). The median recurrence-free follow-up time after inclusion in the $\mathrm{W} \& \mathrm{~W}$ program was 50 months (range 30 months -5 years) at the time of writing.

\section{Distribution of morphologic patterns and evolution over time}

Table 2 shows the distribution of the four morphologic patterns amongst the 164 study patients combined with an overview of any documented changes in morphology over time. At first evaluation (on the restaging scan performed after completion of CRT), no fibrosis (i.e. an apparent normalization of the rectal wall) was observed in a minority of patients $(n=14$, $9 \%)$. The remaining majority of patients $(91 \%)$ showed at least some degree of fibrosis with a minimal fibrotic remnant in $n=104$ (63\%), a full thickness fibrosis in $n=38(23 \%)$, and irregular/spiculated fibrosis in $n=8(5 \%)$. In the majority of patients ( $n=153 / 164,93 \%)$, the morphology of the rectal wall as identified on the first restaging MRI remained stable during long-term follow-up and no changes in pattern, in signal intensity, or in the shape or size of fibrosis were visually observed over time (example shown in Fig. 2). In the remaining 11 patients, some minor changes occurred: in 7 patients, a slight subjectively assessed thickening of the fibrosis occurred
Table 1 Baseline characteristics

\begin{tabular}{|c|c|}
\hline Variable & $\begin{array}{l}\text { No. of patients (total } \\
n=164 \text { ) }\end{array}$ \\
\hline \multicolumn{2}{|l|}{ Sex } \\
\hline Male & 111 \\
\hline Female & 53 \\
\hline Median age (range) & $65(33-84)$ \\
\hline \multicolumn{2}{|l|}{ Histologic tumour type } \\
\hline Adenocarcinoma (solid type) & 164 \\
\hline Adenocarcinoma (mucinous type) & 0 \\
\hline \multicolumn{2}{|l|}{$\begin{array}{l}\text { Primary local tumour stage } \\
\text { (as assessed with MRI) }\end{array}$} \\
\hline \multicolumn{2}{|l|}{ cT-stage } \\
\hline cT1-2 & 43 \\
\hline cT3 & 107 \\
\hline $\mathrm{cT} 4$ & 14 \\
\hline \multicolumn{2}{|l|}{ cN-stage } \\
\hline cNO & 37 \\
\hline $\mathrm{cN} 1$ & 50 \\
\hline $\mathrm{cN} 2$ & 77 \\
\hline \multicolumn{2}{|l|}{ Mesorectal fascia (MRF) involvement } \\
\hline cMRF+ & 57 \\
\hline $\mathrm{cMRF}-$ & 107 \\
\hline $\begin{array}{l}\text { Median tumour length (mm) on primary } \\
\text { staging MRI (range) }\end{array}$ & $39(16-81)$ \\
\hline $\begin{array}{l}\text { Median distance from anorectal junction } \\
(\mathrm{mm}) \text { on primary staging MRI (range) }\end{array}$ & $19(0-135)$ \\
\hline \multicolumn{2}{|l|}{ Neoadjuvant treatment regimen } \\
\hline Long-course chemoradiotherapy* & 154 \\
\hline $5 \times 5 \mathrm{~Gy}+$ prolonged waiting interval & 10 \\
\hline $\begin{array}{l}\text { Median FU in months since inclusion in } \\
\text { watch-and-wait (range) }\end{array}$ & $31(12-80)$ \\
\hline $\begin{array}{l}\text { Median number of FU MRIs since inclusion } \\
\text { in watch-and-wait (range) }\end{array}$ & $7(3-14)$ \\
\hline
\end{tabular}

*The routine chemoradiotherapy scheme consisted of 50.4-Gy radiation combined with $2 \times 825 \mathrm{mg} / \mathrm{m}^{2}$ per day of capecitabine

after the first post-CRT scan; in 1 patient, the fibrosis slightly decreased in volume; and in 3 patients, who initially presented with minor fibrosis, no fibrosis could be reproduced anymore on the subsequent follow-up scans. In all 11 patients, the patterns remained consistent during further follow-up and no further changes were observed. Representative imaging examples are provided in Fig. 3.

\section{Correlation with pretreatment morphology}

Table 3 shows the correlation between the 4 patterns of fibrosis and the primary morphology of the tumour before treatment (as assessed on the baseline staging MRI). Twenty-three percent of patients initially presented with polypoid tumours (Fig. 4a), which were all classified into the 'no fibrosis' $(5 \%)$ 
Table 2 Patterns of response and evolution over time

\begin{tabular}{|c|c|c|c|}
\hline Pattern & $\begin{array}{l}\text { No. of patients } \\
(\%)\end{array}$ & $\begin{array}{l}\text { Change in morphology over time } \\
\text { (No. of patients) }\end{array}$ & $\begin{array}{l}\text { Mean time to change in } \\
\text { morphology* }\end{array}$ \\
\hline 1. No fibrosis & $14(9 \%)$ & None $(n=14)$ & N/A \\
\hline \multirow[t]{4}{*}{ 2. Minimal fibrosis } & $104(63 \%)$ & None $(n=93)$ & $\mathrm{N} / \mathrm{A}$ \\
\hline & & Minor thickening of fibrosis $(n=7)$ & $\begin{array}{l}4.9 \text { months }(2,2,3,3,4,5 \text {, } \\
\text { and } 13 \text { months })^{\#}\end{array}$ \\
\hline & & Minor decrease in fibrosis $(n=1)$ & 5.0 months $^{\#}$ \\
\hline & & $\begin{array}{l}\text { Normalization (fibrosis no longer } \\
\quad \text { visible) } \mid(n=3)\end{array}$ & $\begin{array}{l}10.3 \text { months }(5,5 \text {, and } \\
20 \text { months })\end{array}$ \\
\hline $\begin{array}{l}\text { 3. Full thickness } \\
\text { fibrosis }\end{array}$ & $38(23 \%)$ & None $(n=38)$ & N/A \\
\hline 4. Irregular fibrosis & $8(5 \%)$ & None $(n=8)$ & $\mathrm{N} / \mathrm{A}$ \\
\hline
\end{tabular}

* Mean number of months from the first post-CRT MRI to the timepoint at which the change in morphology was observed. Numbers between parentheses are the actual number of months for the individual patients concerned

\# In all patients $(n=11)$ in whom a change in morphology was observed at a certain time point, no further changes occurred on the further subsequent follow-up scans. None of these patients experienced a local tumour regrowth

N/A not applicable or 'minimal fibrosis' $(18 \%)$ pattern groups after CRT. The majority of patients $(66 \%)$ initially presented with semicircular tumours (Fig. 4b), most of which proceeded into the 'minimal fibrosis' $(41 \%)$ or 'full thickness fibrosis' $(18 \%)$ subgroups after CRT. Only $10 \%$ of patients initially presented with more bulky and irregular tumours (Fig. 4c). These tumours were also relatively larger in size at baseline (mean size $55 \mathrm{~mm}$ versus $40 \mathrm{~mm}$ for the semi-circular and $27 \mathrm{~mm}$ for the polypoid tumours).

\section{Interobserver agreement}

Agreement between the two readers in determining the morphologic patterns was excellent $(\kappa 0.90)$. Discrepancies occurred in only $9 / 164$ patients (5\%). Consensus was easily reached for these cases after discussion of the cases with the third expert reader.

\section{Discussion}

The results of this study, based on an evaluation of over 1500 clinical MRI examinations, show that in the vast majority of rectal cancer patients with a clinical complete response after chemoradiotherapy, at least some fibrotic remnant remains visible in the rectal wall at the site of the previous tumour bed on T2W MRI, which typically remains completely stable during follow-up apart from some almost negligible changes in the subjectively assessed size of fibrosis in a small minority of patients. A minimal fibrotic remnant confined to the bowel wall was the predominant pattern (present in 63\%), followed by patients presenting with full thickness $(23 \%)$ or irregular/ spiculated (5\%) fibrosis. A complete absence of fibrosis with apparent normalization of the rectal wall was observed in only
$9 \%$ of patients at restaging. In an additional 3 patients, some fibrosis was initially observed which could not be reproduced later during follow-up (after a mean interval of 10 months), adding up to a total of $10 \%$ of patients with an apparently normalised wall without any visible fibrosis.

The distribution of morphologic patterns in our current study is largely in line with that previously reported in a smaller patient cohort, although the percentage of patients without fibrosis was somewhat larger (26\%) in this previous cohort, likely due to the small overall sample size $(n=19)$ [8]. Consistent with the previous report, the majority of patients in our study presented with only a minimal fibrotic remnant within the bowel wall. This makes sense, as it has also previously been shown that - when looking at the whole spectrum of patients undergoing chemoradiotherapy for locally advanced disease - tumours that regress into a small, focal fibrotic remnant within the rectal wall have a relatively high chance of complete response $( \pm 50 \%)$ [10]. At baseline, these tumours are typically relatively small and localised to a certain (polypoid or semi-circular) area of the rectal wall, as illustrated in Table 3. Tumours that show more irregular/spiculated fibrosis after CRT have been previously reported to still contain viable residual tumour in the majority of cases $( \pm 80 \%)$ [10]. This probably also explains why the latter group, with thus a relatively low complete response chance, was also underrepresented in our current study cohort consisting exclusively of complete responders.

Our study was primarily intended to establish the range and distribution of morphological appearances of a complete response and to document whether any changes in morphology are to be expected in patients with a sustained complete response during long-term ( $>2$ years) follow-up. Based on the findings of our study, we now know that the morphology as established at restaging 

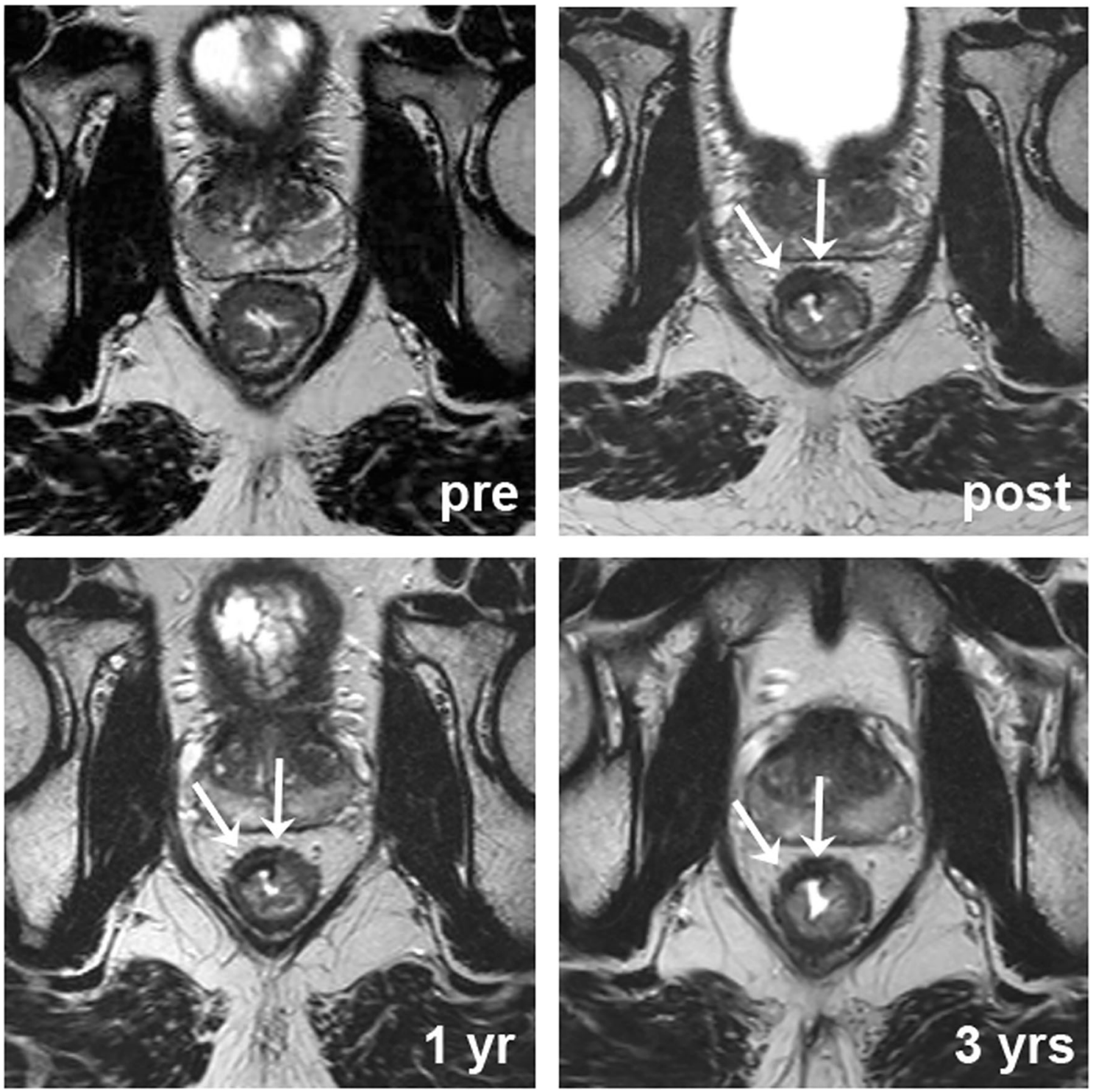

Fig. 2 Example of a patient with a semi-circular tumour in the rectal wall pretreatment that regressed into a minimal fibrotic remnant confined to the rectal on the post-treatment scan (white arrows). The aspect of the fibrosis remained completely unchanged after 1 year and 3 years of follow-up

typically remains consistent over time. In the minority of patients $(n=11,7 \%)$ in whom we did observe some slight thickening or decrease in fibrosis over time upon subjective visual evaluation, these changes were very subtle (almost negligible) and mainly occurred early during followup, after a mean interval of 5 months. All 11 patients were from the 'minor fibrosis' group, which is likely related to the fact that this was by far the biggest subgroup in our cohort. As all 11 patients continued to have a complete remission on further follow-up, these very minor changes may probably be neglected and are within the range of 'normal' variations. With this in mind, any more significant change in signal or size should thus raise the suspicion of a local tumour regrowth, in which case patients need to be referred for endoscopy and further clinical (and biopsy) confirmation, before proceeding to salvage surgery. Detailed assessment of the morphology of patients presenting with recurrent disease was outside the scope of the current study. In addition to morphology, evaluation of diffusion-weighted images has been reported to be potentially helpful to detect early regrowths as an increase in DWI signal may precede visible changes in morphology on T2-weighted MRI, albeit at a risk for false positive findings in some cases [7]. Moreover, DWI is known to improve the performance of MRI to differentiate areas of viable tumour within post-radiation fibrosis, as has been shown by several studies on restaging of rectal cancer after chemoradiotherapy [11-14]. In the recently published consensus guidelines on rectal MRI by the European Society of Gastrointestinal and Abdominal 

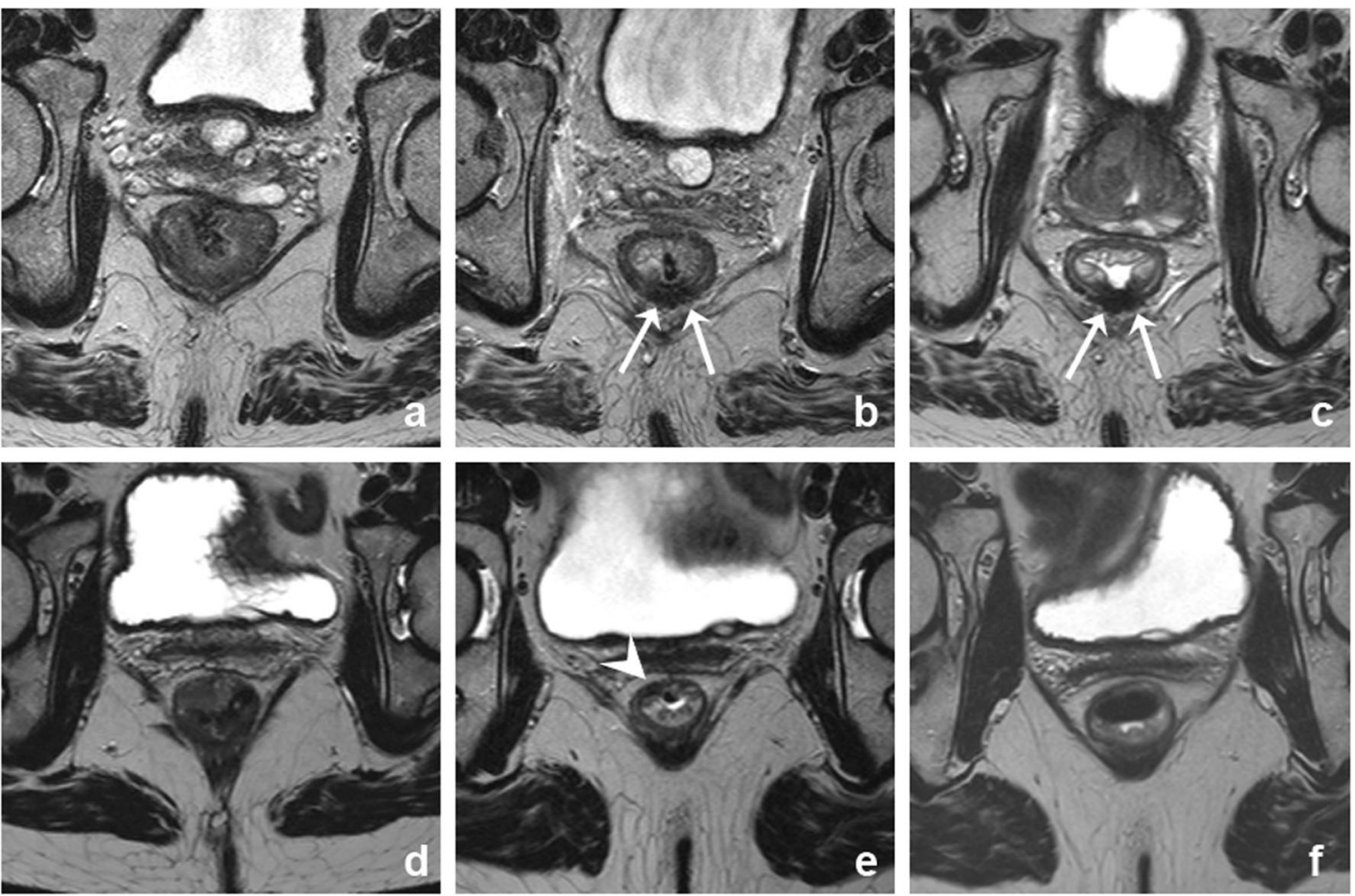

Fig. 3 Two examples of patients in whom some slight changes in morphology were observed over time. The upper row shows a male patient with a semi-circular tumour before treatment (a) who presented with a minimal fibrotic remnant in the rectal wall on the first restaging scan (arrows in b). After 3 months, some slight thickening of the fibrosis occurred (arrows in c) which remained consistent on further follow-up imaging. The bottom row shows a female patient with a polypoid tumour before treatment (d). On the initial restaging scan, a minimal fibrotic remnant was observed (arrowhead in e) that could not be reproduced anymore on the scan performed after 6 months (f), a pattern that remained consistent during further follow-up

challenging in the follow-up setting as the majority of nodes in complete responding patients disappear or decrease to less than $5 \mathrm{~mm}$ in size, which has been shown to be a relatively accurate predictor of a yN0 status with reported negative predictive values of $>90 \%$ [16]. Furthermore, nodal recurrences (without a concomitant luminal regrowth) constitute only a small minority of $3 \%$ of all local regrowths [6]. Finally, as discussed above, we did not include a direct comparison of the morphology of complete responders to the imaging findings of patients with a regrowth as this was outside the scope of the current study and will be addressed by future studies.

In conclusion, we have confirmed that the vast majority of patients with a sustained clinical complete response after
Table 3 Correlation between patterns of fibrosis and pretreatment morphology of the tumour at primary staging

\begin{tabular}{|c|c|c|c|c|c|c|}
\hline \multicolumn{2}{|l|}{ Pattern pre-CRT } & \multicolumn{4}{|c|}{ Pattern post-CRT } & \multirow[t]{3}{*}{ Total } \\
\hline & & \multirow[t]{2}{*}{ No fibrosis } & \multicolumn{3}{|l|}{ Fibrosis } & \\
\hline Pattern & $($ Mean size $\pm \mathrm{SD})$ & & Minimal & Full thickness & Irregular & \\
\hline Polypoid & $27 \pm 7 \mathrm{~mm}$ & $8(5 \%)$ & $30(18 \%)$ & $0(0 \%)$ & $0(0 \%)$ & $38(23 \%)$ \\
\hline Semi-circular & $40 \pm 9 \mathrm{~mm}$ & $6(4 \%)$ & $68(41 \%)$ & $30(18 \%)$ & $5(3 \%)$ & $109(66 \%)$ \\
\hline Bulky/irregular & $55 \pm 8 \mathrm{~mm}$ & $0(0 \%)$ & $6(4 \%)$ & $8(5 \%)$ & $3(2 \%)$ & $17(10 \%)$ \\
\hline
\end{tabular}



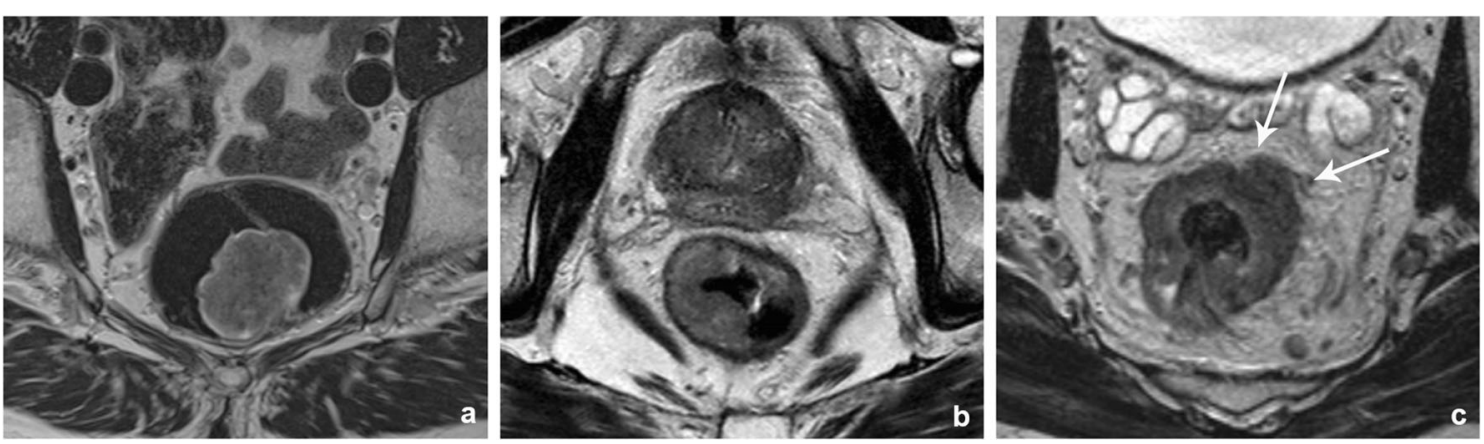

Fig. 4 Primary tumour patterns observed at baseline staging MRI: (a) polypoid tumour mass (with stalk attachment to the rectal wall at 5 o'clock), (b) semi-circular tumour mass (from 6 until 12 o'clock with regular margins), (c) bulky (almost completely circular) tumour mass with irregular margins and nodular extension into the perirectal fat on the left anterior side chemoradiotherapy present with fibrosis with the predominant pattern being a minimal fibrotic remnant that remains confined to the rectal wall. A complete absence of fibrosis (i.e. apparent normalization of the rectal wall) occurs in only $10 \%$ of the cases. Typically, the morphology as established at restaging remains completely unchanged during further follow-up. Once validated in independent cohorts, these findings can serve as a reference for future studies and for the clinical follow-up of patients undergoing watch-and-wait.

Funding The authors state that this work has not received any funding.

\section{Compliance with ethical standards}

Guarantor The scientific guarantor of this publication is Doenja Lambregts.

Conflict of interest The authors of this manuscript declare no relationships with any companies, whose products or services may be related to the subject matter of the article.

Statistics and biometry No complex statistical methods were necessary for this paper.

Informed consent Written informed consent was waived by the Institutional Review Board.

Ethical approval Institutional Review Board approval was obtained.

Study subjects or cohorts overlap The study patients were all selected from consecutive cohorts of previously reported and ongoing clinical trials focussing on the oncological and functional outcome of a watchand-wait policy (Maas et al JCO 2011, Martens et al J Natl Cancer Inst 2016, van der Valk et al Lancet 2018, and an ongoing clinical study registered at clinical trials.gov under NCT03426397). In addition, 47 of the patients included in the current study were included in a previous study on the use of MRI+DWI to detect local tumour regrowths during follow-up (Lambregts et al Eur Rad 2016). This previous study concerned a diagnostic accuracy study focussing on detecting recurrent tumours with a specific focus on DWI, while the current report is a descriptive study focussing on T2W morphology which included only non-recurrent patients.

\section{Methodology}

- Retrospective

- Diagnostic or prognostic study

- Multicentre study

\section{References}

1. Habr-Gama A, Perez RO, Nadalin W et al (2014) Operative versus nonoperative treatment for stage 0 distal rectal cancer following chemoradiation therapy: long-term results. Ann Surg 240:711717 discussion 7-8

2. Martens MH, Maas M, Heijnen LA et al (2016) Long-term outcome of an organ preservation program after neoadjuvant treatment for rectal cancer. J Natl Cancer Inst 108

3. Smith JD, Ruby JA, Goodman KA et al (2012) Nonoperative management of rectal cancer with complete clinical response after neoadjuvant therapy. Ann Surg 256:965-972

4. Appelt AL, Ploen J, Harling H et al (2015) High-dose chemoradiotherapy and watchful waiting for distal rectal cancer: a prospective observational study. Lancet Oncol 16:919-927

5. Hupkens BJP, Martens MH, Stoot JH et al (2017) Quality of life in rectal cancer patients after chemoradiation: Watch-and-Wait Policy versus standard resection - a matched-controlled study. Dis Colon Rectum 60:1032-1040

6. van der Valk MJM, Hilling DE, Bastiaannet E et al (2018) Longterm outcomes of clinical complete responders after neoadjuvant treatment for rectal cancer in the International Watch \& Wait Database (IWWD): an international multicentre registry study. Lancet 391:2537-2545

7. Lambregts DM, Lahaye MJ, Heijnen LA et al (2016) MRI and diffusion-weighted MRI to diagnose a local tumour regrowth during long-term follow-up of rectal cancer patients treated with organ preservation after chemoradiotherapy. Eur Radiol 26:2118-2125

8. Lambregts DM, Maas M, Bakers FC et al (2011) Long-term followup features on rectal MRI during a wait-and-see approach after a clinical complete response in patients with rectal cancer treated with chemoradiotherapy. Dis Colon Rectum 54:1521-1158

9. Maas M, Beets-Tan RG, Lambregts DM et al (2011) Wait-and-see policy for clinical complete responders after chemoradiation for rectal cancer. J Clin Oncol 2011(29):4633-4640

10. Lambregts D, Delli Pizzi A, Lahaye M et al (2018) A pattern-based approach combining tumor morphology on MRI with distinct signal patterns on diffusion-weighted imaging to assess response of rectal tumors after chemoradiotherapy. Dis Colon Rectum 61:328337 
11. Kim SH, Lee JM, Hong SH et al (2009) Locally advanced rectal cancer: added value of diffusion-weighted MR imaging in the evaluation of tumor response to neoadjuvant chemo- and radiation therapy. Radiology 253:116-125

12. Lambregts DM, Vandecaveye V, Barbaro B et al (2011) Diffusionweighted MRI for selection of complete responders after chemoradiation for locally advanced rectal cancer: a multicenter study. Ann Surg Oncol 18:2224-2231

13. Song I, Kim SH, Lee SJ, Choi JY, Kim MJ, Rhim H (2012) Value of diffusion-weighted imaging in the detection of viable tumor after neoadjuvant chemoradiation therapy in patients with locally advanced rectal cancer: comparison with T2-weighted and PET/CT imaging. Br J Radiol 85:577-586

14. Foti PV, Privitera G, Piana S et al (2016) Locally advanced rectal cancer: qualitative and quantitative evaluation of diffusion- weighted MR imaging in the response assessment after neoadjuvant chemo-radiotherapy. Eur J Radiol Open 3:145-152

15. Beets-Tan RGH, Lambregts DMJ, Maas M et al (2018) Magnetic resonance imaging for clinical management of rectal cancer: updated recommendations from the 2016 European Society of Gastrointestinal and Abdominal Radiology (ESGAR) consensus meeting. Eur Radiol 28:1465-1475

16. Heijnen LA, Maas M, Beets-Tan RG et al (2016) Nodal staging in rectal cancer: why is restaging after chemoradiation more accurate than primary nodal staging? Int J Colorectal Dis 31:1157-1162

Publisher's note Springer Nature remains neutral with regard to jurisdictional claims in published maps and institutional affiliations. 